SEP 291998

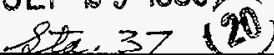

2. To: (Receiving Organization)

Distribution

5. Proj./Prog./Dept./Div.:

Natural Phenomena Hazards

8. Originator Remarks:

Straight-wind hazard assessment to support Hanford Site design criteria

11. Receiver Remarks: 11A. Design Baseline Document? [] Yes [X] No

$\begin{aligned} & \text { 3. From: (Originating Organization) } \\ & 8 C 400\end{aligned}$
$\begin{aligned} & \text { 4. Related EDT No.: } \\ & \text { N/A }\end{aligned}$

6. Design Authority/ Design Agent/Cog. Engr.:

T.J. Conrads

N/A
7. Purchase Order No.:

9. Equip./Component No.:

N/A

10. Systen/Blidg./Facil ity: Hanford Site Natural Hazards Phenomena

12. Major Assm. Dwg. No.:

$N / A$

13. Permit/Permit Application Ho.: N/A

14. Required Response Date:

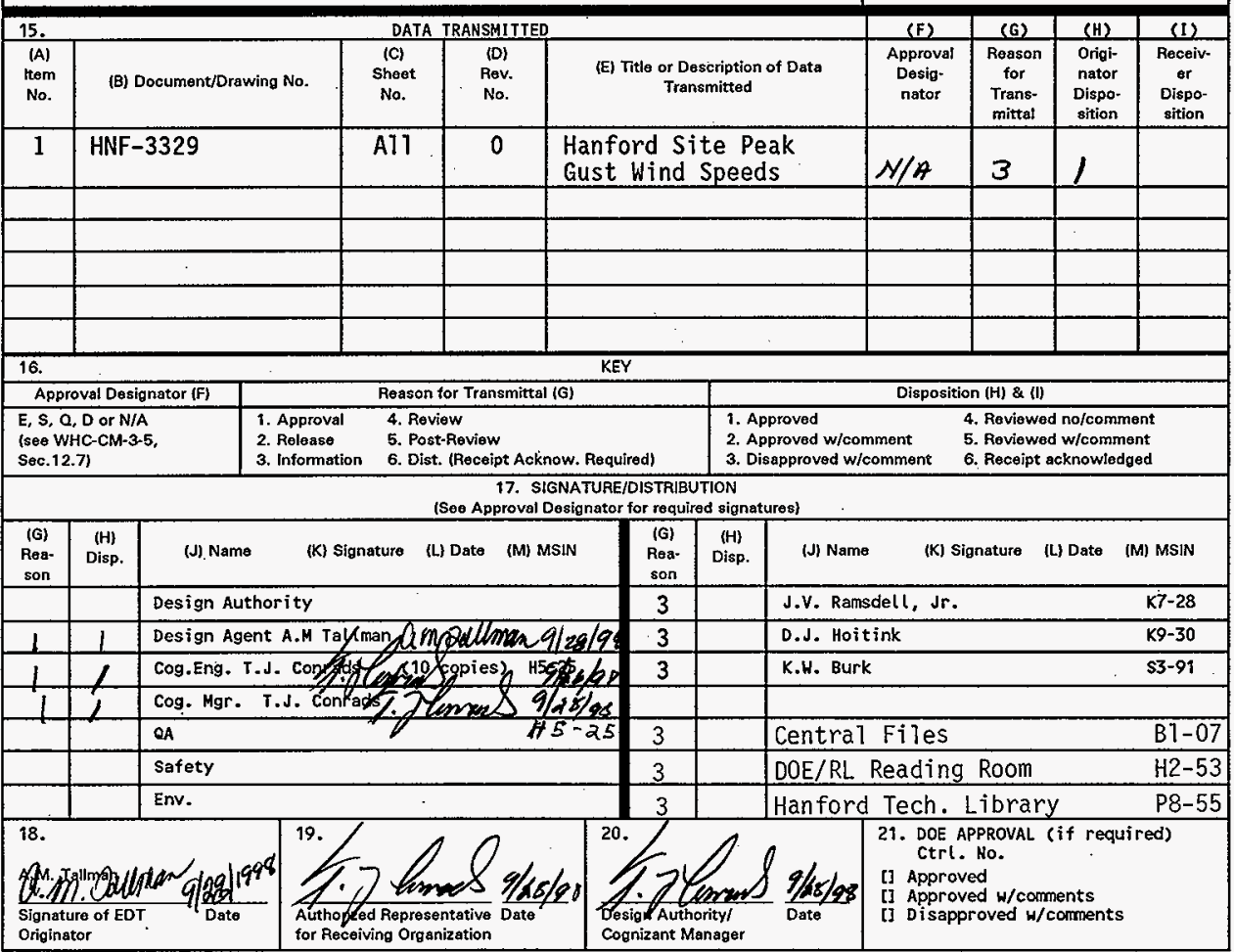

BD-7400-172-2 (05/96) GEF097 


\section{Hanford Site Peak Gust Wind Speeds}

J.V. Ramsdel1, Jr.

Pacific Northwest National Laboratory, Richland, WA 99352

U.S. Department of Energy Contract DE-ACO6-96RL13200

\begin{tabular}{|c|c|c|c|}
\hline $\begin{array}{l}\text { EDT/ECN: } \\
\text { Org Code: } \\
\text { B\&R Code: }\end{array}$ & $\begin{array}{l}\text { EDT-625594 } \\
8 C 400 \\
\text { EW3130010 }\end{array}$ & $\begin{array}{l}\text { UC: } 2000 \\
\text { Charge Code: } \\
\text { Total Pages: }\end{array}$ & $\begin{array}{l}\text { D2D31 / HANA2600 } \\
15\end{array}$ \\
\hline
\end{tabular}

Key Words: Gusts; wind hazards; design wind speeds; Hanford wind data

Abstract: Peak gust wind data collected at the Hanford Site since 1945 are analyzed to estimate maximum wind speeds for use in structural design. The results are compared with design wind speeds proposed for the Hanford Site. These comparisons indicate that design wind speeds contained in a January 1998 advisory changing DOE-STD-1020-94 are excessive for the Hanford Site and that the design wind speeds in effect prior to the changes are still appropriate for the Hanford Site.

TRADEMARK DISCLAIMER. Reference herein to any specific commercial product, process, or service by trade name, trademark, manufacturer, or otherwise, does not necessarity constitute or imply its endorsement, recommendation, or favoring by the United States Government or any agency thereof or its contractors or subcontractors.

Printed in the United States of America. To obtain copies of this document, contact: Document Control Services, P.0. Box 950, Mailstop H6-08, Richland WA 99352, Phone (509) 372-2420; Fax (509) 376-4989.
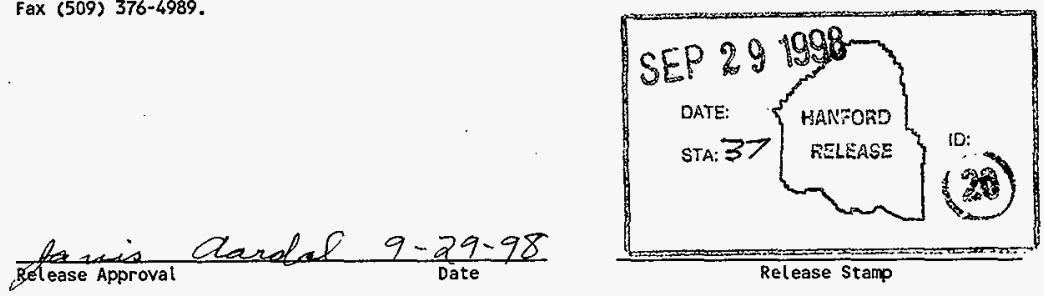

\section{Approved for Public Release}




\section{CONTENTS}

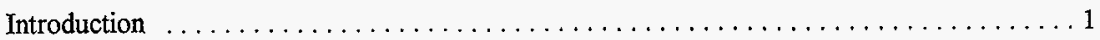

Hanford Peak Gust.Wind Data . . . . . . . . . . . . . . . . . . . . . . . 2

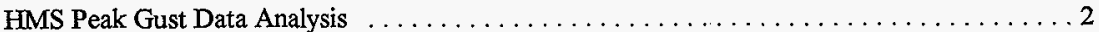

HMS Plus Telemetry Stations Data Analysis . . . . . . . . . . . . . . . . 4

Comparison of HMS Data Analysis and DOE Guidance $\ldots \ldots \ldots \ldots \ldots \ldots \ldots$

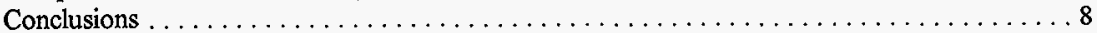

References . . . . . . . . . . . . . . . . . . . . . . . . . . . . 10

Appendices

A. Annual Peak Gusts at the 50-foot $(15.2 \mathrm{~m})$ Level of the Hanford Meteorology Station

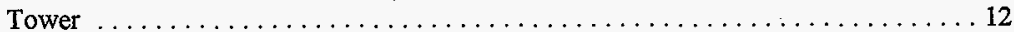

B. Annual 10-m Peak Gust Data (mph) for Hanford Telemetering Stations with dates and times. . . . . . . . . . . . . . . . . . . . . . . . . . . . .

\section{TABLES}

1. Fisher-Tippet Type I distribution parameter estimates for extreme winds at $10 \mathrm{~m}$ based on data from the 50 -foot level of the HMS Tower . . . . . . . . . . . . . . . . . 4

2. Extreme wind estimates for the $10 \mathrm{~m}$ level analyses of data from the 50-foot level of the

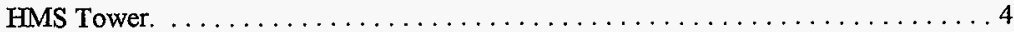

3. Fisher-Tippet Type I distribution parameter maximum likelihood estimates for extreme winds at $10 \mathrm{~m}$ for the combined data set. $\ldots \ldots \ldots \ldots \ldots \ldots \ldots \ldots \ldots \ldots$

4. Extreme wind estimates from the analysis of the $10-\mathrm{m}$ level combined data. . . . . . 7

5. Comparison of design wind speeds ( $\mathrm{mph}$ ) for the Hanford Site. . . . . . . . . . . 8

\section{FIGURES}

1. HMS Tower peak gust data and extreme wind speed analyses. . . . . . . . . . . 3

2. Hanford Meteorology Station telemetry network.................. 5

3. Results of the maximum likelihood analysis of the combined peak gust data. . . . . . 7

4. Design wind speed comparison with Hanford Site data . . . . . . . . . . . . . 9 
HNF-3329, Rev. 0

\section{Hanford Site Peak Gust Wind Speeds}

\section{Introduction}

The U.S. Department of Energy Office of Nuclear Safety Policy and Standards distributed an Interim Advisory on Straight Wind and Tornadoes (Advisory) (DOE 1998) on January 22, 1998 that revised Table 3.2 in DOE-STD-1020-94 (DOE 1994). The Advisory, combined with a 1996 Change notice, revised design wind speed criteria for the Hanford Site by changing the basis for the criteria from the fastest mile wind speed to peak gusts and by increasing the design wind speeds for performance categories (PC) PC-2, PC-3, and PC-4 following Table C6-5 of ASCE 7-95 (ASCE, 1995). The design wind speed for PC-1 was unchanged.

The change in the basis for the design criteria reflects a change in meteorological data collection and recording practices of the National Weather Service. Fastest mile wind speeds are no longer reported. They have been replaced by peak gusts. The peak gust is the fastest observed speed in any time period. However, it is not an instantaneous wind speed because of the inertia of the instrument used for wind speed measurements and the averaging inherent in the electronics used to process and record the measurements. Considering the characteristics of the instruments and electronics, peak gusts reported in climatological data have been estimated to be about $3 \mathrm{sec}$ average gusts.

Design wind speeds in the ASCE 7-95 and the Advisory are based on an analysis of Peterka and Shahid (1998) using the superstation concept described by Peterka (1992). Other than the combination of data in to superstations, the analytical methods used by Peterka and Shahid are standard methods used for estimating extreme values. Climatological data for 487 stations having peak gust records were obtained from the National Climatic Data Center for the analysis. The periods of record for the peak gusts for individual stations ranged from 5 to 45 years. Data for the individual stations were adjusted to a standard $10-\mathrm{m}$ height and combined into superstations having 25 to 510 station years of data. The records were combined to reduce the uncertainty in the estimates of low probability peak gust wind speeds. The uncertainty decreases as $1 / n^{0.5}$, where $n$ is the number of years of data included in the analysis. According to Peterka and Shahid, most of the superstations had 50 to 200 station years of data. Potential data sets from eastern Washington are limited. Topographic features in the vicinity of Yakima and Walla Walla National Weather Service stations are likely to affect peak gusts recorded at the stations and limit the utility of the data for estimating gusts at Hanford.

Wind data from the Hanford Site were not included in the analysis of Peterka and Shahid. This report presents an analysis of peak gust wind data collected at the Hanford Site since 1945. The results of the data analysis show that the design wind speeds for the Hanford Site set forth in the Advisory, which are based on the analysis of Peterka and Shahid, are excessive. 
HNF-3329, Rev. 0

\section{Hanford Peak Gust Wind Data}

Meteorological measurements have been made at the Hanford Meteorological Station on the Hanford Site since the middle 1940s. The measurements are made by the Meteorological and Climatological Services Project conducted by the Pacific Northwest National Laboratory (PNNL) for the U.S. Department of Energy. National Weather Service procedures and a formal Quality Assurance Plan (ETD-018, Rev. ) are followed in data collection and processing, and instruments are calibrated on a regular basis by PNNL Craft Services personnel. Supplemental meteorological measurements are made at more than 25 telemetered monitoring stations located on and near the site. Glantz and Islam (1988) and Glantz, et al. (1990) present detailed description of the supplemental stations. Meteorological and climatological data summaries are published annually; Hoitink and Burk (1998) is the most recent summary

Peak gust data dating back to 1945 are available for the $50 \mathrm{ft}$ level of the Hanford Meteorological Station (HMS) Tower located between the 200 East and 200 West areas. These data are listed in Appendix A. Assuming that the relationship for adjusting gust speeds for measurement height given by Peterka and Shahid is correct, the adjustment factor to correct the $50 \mathrm{ft}$ level peak gusts in Appendix A to $10 \mathrm{~m}$ is 0.9543 . Peak gust data are available for telemetered stations located on and near the Hanford Site from September 1994 to date. Annual peak gust data for all of these stations are listed in Appendix B.

\section{HMS Peak Gust Data Analysis}

Extreme winds are generally estimated using either a Fisher-Tippet Type I or FisherTippet Type II distribution. Peterka and Shahid use a Fisher-Tippet Type I distribution in their analysis for all stations. The Fisher-Tippet Type I distribution has two parameters - a location parameter $\mu$ and a scale parameter $\sigma$. Given the location and scale parameters, wind speeds can be calculated for various return periods using the relationship

$$
\mathrm{U}_{\mathrm{N}}=\mu-\sigma \ln [-\ln (1-1 / \mathrm{N})]
$$

where $U_{\mathrm{N}}$ is the wind speed with an $\mathrm{N}$-year return period. The probability that a wind speed with a return period of $\mathrm{N}$ years will be exceeded in any single year is $1 / \mathrm{N}$. Following the lead of Peterka and Shahid, a Fisher-Tippet Type I (Gumbel) distribution was fit to the corrected peak gusts from the HMS Tower using the method of moments described by Simiu and Scanlan (1986). There are two other commonly used methods for estimating the parameters of the FisherTippet Type I distribution. These methods are the maximum likelihood method (see Kinnison 1985 or Ramsdell, et al. 1986), and a method by Lieblein (1954) and (1974) based on order statistics (see IAEA 1.981). The method of moments is the simplest method to use, but in a statistical sense, it is a relatively inefficient method for estimating the scale parameter. Figure 1 shows the HMS peak gust data and curves presenting the results of all three methods for estimating distribution parameters. 
HNF-3329, Rev. 0

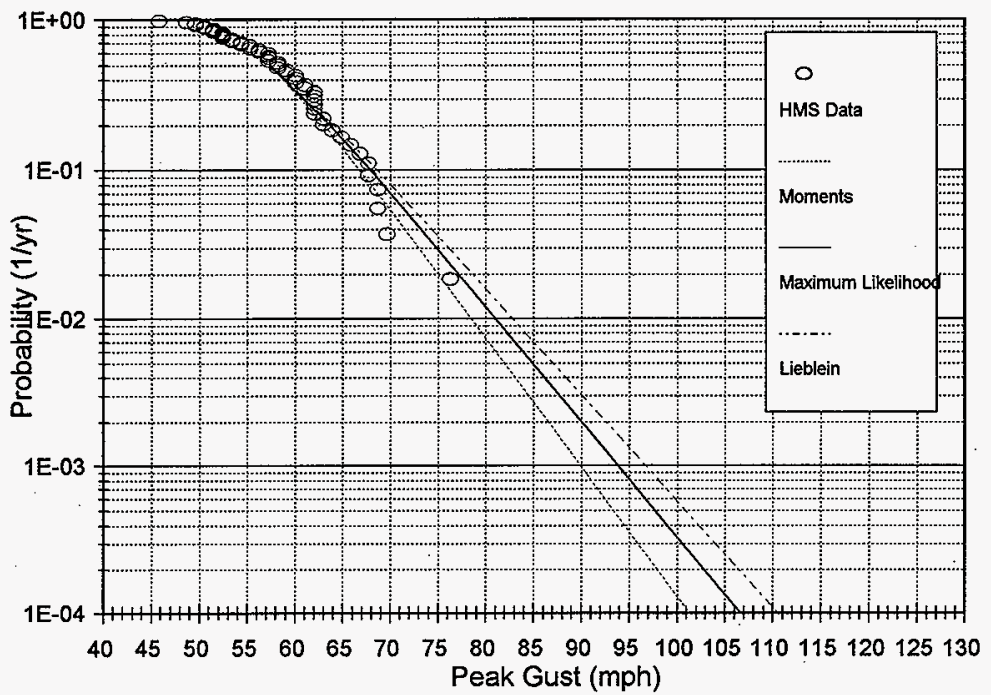

Figure 1. HMS Tower peak gust data and extreme wind speed analyses.

The results of the three methods of estimating distribution parameters are compared in Table 1. All three methods give similar location parameter estimates, which is to be expected because all methods estimate the location parameter efficiently. In contrast, the three methods give scale parameters that differ significantly. The lowest scale parameter is given by the method of moments, which makes the least efficient use of the data in estimating the scale parameter. Lieblein's method gives the largest scale parameter. The maximum likelihood method, which makes the most efficient use of the data, gives a scale parameter that is between the scale parameters calculated with the other methods. See Johnson and Kotz (1971).

The extreme winds calculated using these sets of parameters increase in the order of increasing scale parameter because the differences among the location parameters are small. The extreme wind estimates are listed in Table 2 . The parameters estimated using the maximum likelihood method are recommended for extreme wind calculations at the Hanford Site because they make most efficient use of the data. 
HNF-3329, Rev. 0

Table 1. Fisher-Tippet Type I distribution parameter estimates for extreme winds at $10 \mathrm{~m}$ based on data from the 50 -foot level of the HMS Tower.

\begin{tabular}{|l|c|c|c|}
\hline \multirow{2}{*}{ Parameter } & \multicolumn{3}{|c|}{ Parameter Estimation Method } \\
\cline { 2 - 4 } & Moments & Maximum Likelihood & Lieblein \\
\hline Location $(\mathrm{mph})$ & 55.66 & 55.48 & 55.14 \\
\hline Scale $(\mathrm{mph})$ & 4.96 & 5.56 & 6.02 \\
\hline
\end{tabular}

Table 2. Extreme wind estimates for the $10 \mathrm{~m}$ level analyses of data from the 50foot level of the HMS Tower. The standard deviations of the uncertainty of the estimates for a 50-year return period are shown in parentheses.

\begin{tabular}{|c|c|c|c|}
\hline \multirow{2}{*}{$\begin{array}{c}\text { Retum Period } \\
\text { (yrs) }\end{array}$} & Moments & Maximum Likelihood & Lieblein \\
\cline { 2 - 4 } & 70.4 & 72.0 & 73.0 \\
\hline 20 & $75.0(2.9)$ & $77.2(2.5)$ & $78.6(3.2)$ \\
\hline 50 & 78.5 & 81.1 & 82.8 \\
\hline 100 & 89.9 & 93.9 & 96.7 \\
\hline 1,000 & 101.3 & 106.7 & 110.6 \\
\hline 10,000 & & & \\
\hline
\end{tabular}

\section{HMS Plus Telemetry Stations Data Analysis}

In addition to the HMS tower peak gust data, 10-m gust data are available for telemetered stations located on and near the Hanford Site from September 1994 to date. The locations of the stations in the Hanford telemetry network are shown in Figure 2. Annual peak gust data for all of these stations are listed in Appendix B.

Of the telemetering stations, 18 stations located on or near the Hanford Site provide wind measurements that are considered representative for building design purposes for the Hanford Site. The data for these stations (stations 1, 3 through 7, 9 through 14, 18, 22 through 25, and 27) were used to supplement the HMS station data in a second analysis using the method of moments to evaluate the parameters of the distribution of the extreme winds. The data for the 
HNF-3329, Rev. 0

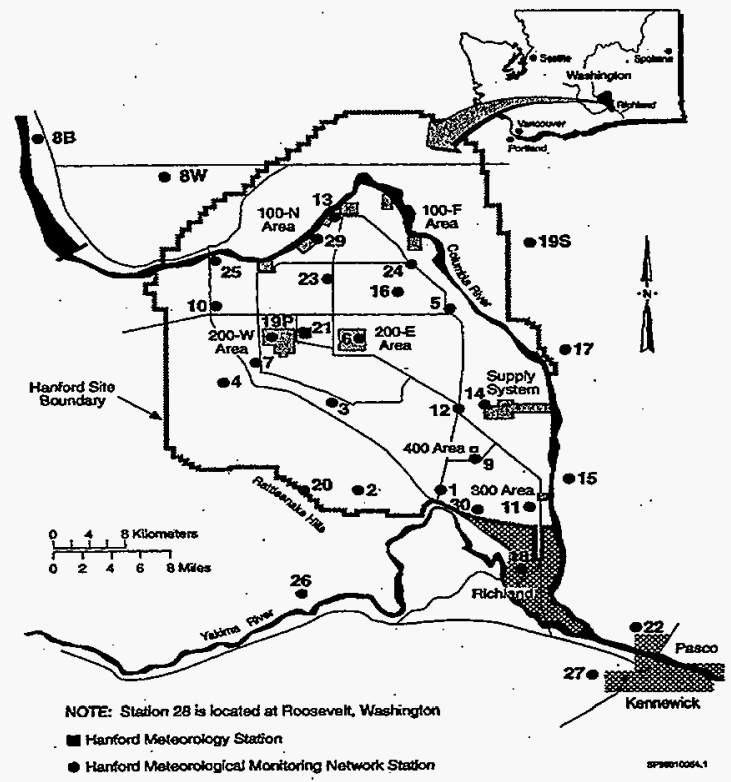

Figure 2. Hanford Meteorology Station telemetry network.

fall of 1994 were combined with the data for 1998 and treated as data for a single year by selecting the maximum wind speed for each station. As a result, the supplemental data set consists of 72 station-years of peak gusts.

Peterka and Shahid (1998) claim, based on the analysis of Peterka (1992) and others, that extreme wind data from different stations may be combined because the peak gusts tend to be uncorrelated. The discussion of this point in Peterka (1992) is limited; the issue needs a more thorough evaluation. Nevertheless, Peterka and Shahid combine the data from several stations into "superstations" for analysis. The stations in the Hanford telemetry system are closer together 
than the stations used by Peterka and Shahid. Therefore, the dates and times of the peak gusts at the telemetry stations were examined for evidence of correlation. Typically, the peak gusts occurred on several days during the fall, winter, and spring seasons with several stations reporting their annual maximum gust on the same day, and even during the same 15-minute time period. As a result, peak gusts measured on the same day (or in the same storm if near midnight) were considered correlated. In these cases only one gust for the day was included in the analysis. Initially the median gust was selected but ultimately the maximum gust was chosen to be conservative. Excluding all gusts other than the maximum for each day reduced the size of the supplemental data set to 20 station days. These 20 gusts were combined with the HMS data for analysis.

The results of the maximum likelihood analysis of the combined data set are shown in Tables 3 and 4. Table 3 contains the Fisher-Tippet Type I parameter estimates for the combined data set, and Table 4 contains peak gust estimates for selected return periods. The parameter values and peak gust estimates for the HMS data alone are repeated in these tables for comparison. Figure 3 shows the results of the analysis graphically. Statistically, the differences between the results using the combined data and the HMS data alone are insignificant.

The rationale for not considering the data from the remaining stations is as follows. The HMS, which is station 21 , is considered separately because of its long record of observations. Other stations are not considered representative for the following reasons. Stations 16 (Gable Mountain) and 20 (Rattlesnake Mountain) are on exposed peaks and station 2 (Emergency Operations Center) is well above the floor of the Columbia Basin; the winds at these stations are not representative of winds at lower elevations on the site. Similarly, stations 15 (Franklin) and 17 (Ringold) are located on the bluffs to the east of the Hanford Site across the Columbia River and may not be representative of the site. Wind measurements at Station 19 P (Plutonium Finishing Plant) in the 200 West Area are made $8 \mathrm{ft}$ above ground; extrapolation of gusts to the $10 \mathrm{~m}$ level is unwarranted because of nearby measurements at stations 4,7 , and 21 . Stations 8 (Beverly), 26 (Benton City), and 28 (Roosevelt) are separated from the Hanford Site by topographic features that could influence extreme wind climatology. Finally, the periods of record for stations $29(100 \mathrm{~K})$ and 30 (HAMMER) are too short to be considered.

Table 3. Fisher-Tippet Type I distribution parameter maximum likelihood estimates for extreme winds at $10 \mathrm{~m}$ for the combined data set.

\begin{tabular}{|l|c|c|}
\hline Parameter & Combined Data & HMS Tower Data \\
\hline Location (mph) & 55.53 & 55.66 \\
\hline Scale (mph) & 5.62 & 4.96 \\
\hline
\end{tabular}


HNF-3329, Rev. 0

Table 4. Extreme wind estimates from the analysis of the 10-m level combined data.

\begin{tabular}{|c|c|c|}
\hline \multirow{2}{*}{$\begin{array}{c}\text { Return Period } \\
\text { (yrs) }\end{array}$} & \multicolumn{2}{|c|}{ Wind Speed at $10 \mathrm{~m}$} \\
\cline { 2 - 3 } & Combined Data & HMS Tower Data \\
\hline 20 & 72.2 & 72.0 \\
\hline 50 & 77.5 & 77.2 \\
\hline 100 & 81.4 & 81.1 \\
\hline 1,000 & 94.4 & 93.9 \\
\hline 10,000 & 107.3 & 106.7 \\
\hline
\end{tabular}

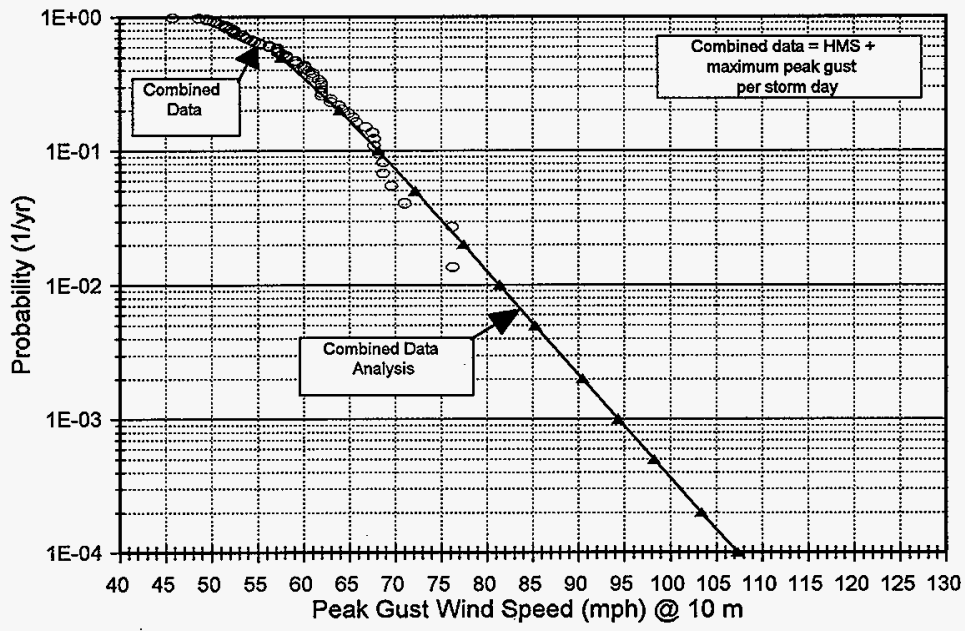

Figure 3. Results of the maximum likelihood analysis of the combined peak gust data. 


\section{Comparison of HMS Data Analysis and DOE Guidance}

U.S. Department of Energy guidance for design wind speeds at the Hanford Site is contained in Table 3.2 of DOE-STD-1020-94 (DOE 1994). Table 5 gives the design wind speeds for the Hanford Site in Table 3.2 prior to and following the Advisory (DOE 1998) based on ASCE 7-95 (ASCE 1995). The increase in design wind speeds for low probability events (long return periods) associated with the Advisory is clearly evident in the table. The final column in the table gives design wind speeds calculated from the Hanford Site peak gust data using parameters estimated by the maximum likelihood method. Figure 4 presents a graphic comparison of the design wind speeds along with the HMS peak gust data

Table 5. Comparison of design wind speeds ( $\mathrm{mph}$ ) for the Hanford Site.

\begin{tabular}{|c|c|c|c|}
\hline $\begin{array}{c}\text { Return Period } \\
\text { (yr) }\end{array}$ & $\begin{array}{c}\text { DOE-STD-1020-94 } \\
\text { Table 3.2 prior to } \\
\text { DOE 1998 }\end{array}$ & $\begin{array}{c}\text { DOE-STD-1020-94 } \\
\text { Table 3.2 following } \\
\text { DOE 1998 }\end{array}$ & $\begin{array}{c}\text { Hanford Site } \\
\text { Peak Gust Data }\end{array}$ \\
\hline 50 & 86.4 & 85 & 77 \\
\hline 100 & 86.4 & 91 & 81 \\
\hline 1,000 & 97.0 & 111 & 94 \\
\hline 10,000 & 107.5 & 128 & 107 \\
\hline
\end{tabular}

\section{Conclusions}

Peak gust wind data from the Hanford Site have been analyzed to estimate extreme wind speeds with recurrence intervals ranging from 20 to 10,000 years. The 53 year record of peak gust at Hanford is longer than the period of record for any single station used in the analysis of Peterka and Shahid (1998). It also exceeds the length of record of 18 "superstations" created by Peterka and Shahid by combining records from separate stations to reduce sampling error.

Three methods were used to estimate the parameters of a Fisher-Tippet Type I extreme value distribution. The methods give consistent estimates of the location and scale parameters of the distribution. Estimates of the uncertainty in the 50-yr extreme wind are in the lower portion of the range of values calculated by Peterka and Shahid for "superstations" with up to 150 station-years of data. These results indicate that the Hanford peak gust data should provide good estimates of extreme winds. 
HNF-3329, Rev. 0

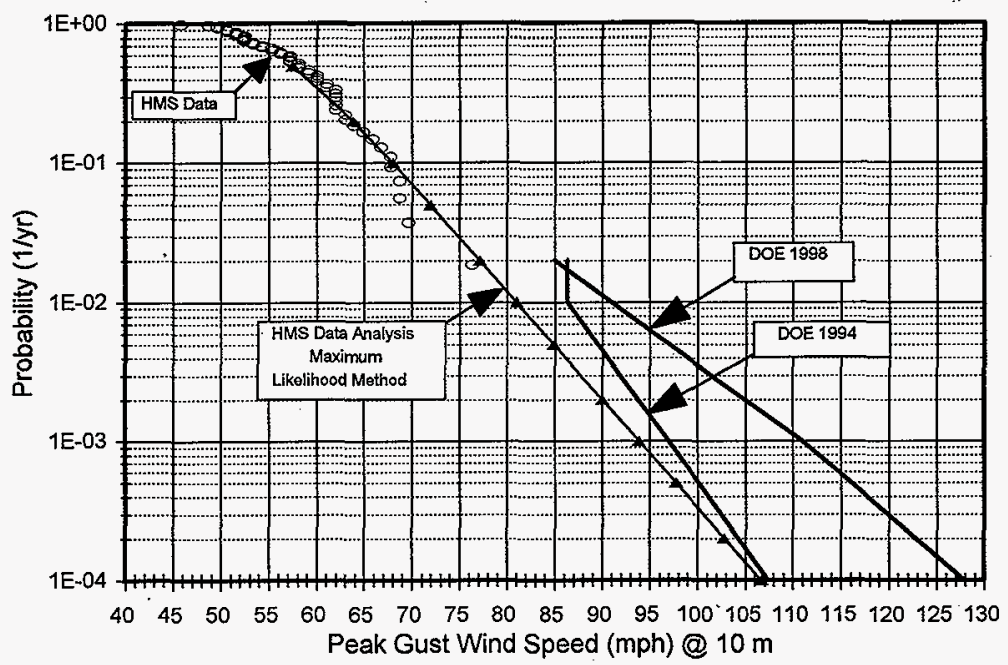

Figure 4. Design wind speed comparison with Hanford Site data.

Extreme wind estimates for Hanford for the 10-m level calculated using any of the sets of parameters fall well below the design wind speeds set forth in recent Department of Energy directives. Design speeds estimated using the method of moments or maximum likelihood parameters also fall below the current design wind speeds for all return periods, and speeds estimated using the Lieblein method fall below the current design wind speeds for recurrence intervals of less than about 400 years. Although the method of moments was used to develop design wind speeds in ASCE 7-95 (ASCE 1995), use of the maximum likelihood method for estimating parameters is recommended for use with the Hanford Site wind data because it makes the most efficient use the available data.

The HMS peak gust data analyses presented above clearly show that the design wind speeds in recent changes to DOE guidance (DOE 1998) are excessive and that the previous guidance is still adequate. Continued use of the previous guidance is recommended. 
HNF-3329, Rev. 0

\section{References}

ASCE. 1995. Minimum Design Loads for Buildings and Other Structures. ASCE 7-95. American Society of Civil Engineers, New York

DOE. 1994. Natural Phenomena Hazards Design and Evaluation Criteria for Department of Energy Facilities. DOE-STD-1020-94. U.S. Department of Energy, Washington, D. C.

DOE. 1998. January 22, 1998 Memorandum. U.S. Department of Energy, Washington, D.C.

Glantz, C. S., and M. M. Islam. 1988. The Data Collection Component of the Hanford Meteorology Monitoring Program. PNL-6684, Pacific Northwest Laboratory, Richland, Washington.

Glantz, C. S., M. N. Schwartz, K. W. Burk, R. B. Kasper, M. W. Ligotke, and P. J. Perrault. 1990. Climatological Summary of Wind and Temperature Data for the Honford Meteorology Monitoring Network. PNL-7471. Pacific Northwest Laboratory, Richland, Washington.

Hoitink, D. J., and K. W. Burk. 1998. Climatological Data Summary 1997, With Historical Data. PNNL-1 1794. Pacific Northwest National Laboratory, Richland, Washington.

IAEA. 1981. Extreme Meteorological Events in Nuclear Power Plant Siting, Excluding Tropical Cyclones. Safety Series No. 50-SG-S11A. International Atomic Energy Agency, Vienna.

Johnson, N. L. and S. Kotz. 1971. Continuous Univariate Distributions - 1. John Wiley \& Sons. New York.

Kinnison, R. R. 1985. Applied Extreme Value Statistics. Battelle Press, Columbus..

Lieblein, J. 1954. "A New Method of Analyzing Extreme Value Data," National Advisory Committee for Aeronautics, Technical Note 3053, Washington, D.C.

Lieblein, J. 1974. "Not on Simplified Estimators for Type 1 Extreme Value Distribution," NBSIR 75-647, National Bureau of Standards, U.S. Department of Commerce, Washington, D.C.

Peterka, J. A. 1992. "Improved extreme wind prediction for the United States." J. Wind Engineering and Industrial Aerodynamics, 41:533-541.

Peterka, J. A., and S. Shahid. 1998. "Design Gust Wind Speeds in the United States." J. Structural Engineering, 124:207-214. 
HNF-3329, Rev. 0

Ramsdell, J. V., D. L. Elliott, C. G. Holladay, and J. M. Hubbe. 1986. Methodology for

Estimating Extreme Winds for Probabilistic Risk Assessments. NUREG/CR-4492, U.S. Nuclear Regulatory Commission, Washington, D.C.

Simiu, E. and R. H. Scanlan. 1986. Wind Effects on Structures. $2^{\text {nd }}$ Ed. Wiley Interscience, New York. 
HNF-3329, Rev. 0

Appendix A. Annual Peak Gusts at the 50-foot (15.2 m) Level of the Hanford Meteorology Station Tower

\begin{tabular}{|c|c|c|c|c|c|c|c|}
\hline \multicolumn{7}{|c|}{ Hanford Meteorology Station Peak Gusts (mph) } \\
\hline Year & Speed & Year & Speed & Year & Speed & Year & Speed \\
\hline 1945 & 55 & 1946 & 54 & 1947 & 60 & 1948 & 71 \\
\hline 1949 & 64 & 1950 & 63 & 1951 & 62 & 1952 & 52 \\
\hline 1953 & 65 & 1954 & 56 & 1955 & 71 & 1956 & 70 \\
\hline 1957 & 72 & 1958 & 58 & 1959 & 55 & 1960 & 59 \\
\hline 1961 & 66 & 1962 & 57 & 1963 & 65 & 1964 & 53 \\
\hline 1965 & 63 & 1966 & 57 & 1967 & 65 & 1968 & 55 \\
\hline 1969 & 60 & 1970 & 53 & 1971 & 65 & 1972 & 80 \\
\hline 1973 & 51 & 1974 & 61 & 1975 & 68 & 1976 & 65 \\
\hline 1977 & 59 & 1978 & 64 & 1979 & 69 & 1980 & 56 \\
\hline 1981 & 66 & 1982 & 60 & 1983 & 65 & 1984 & 62 \\
\hline 1985 & 48 & 1986 & 54 & 1987 & 54 & 1988 & 63 \\
\hline 1989 & 58 & 1990 & 73 & 1991 & 61 & 1992 & 60 \\
\hline 1993 & 67 & 1994 & 52 & 1995 & 61 & 1996 & 55 \\
\hline 1997 & 72 & 1998 & & 1999 & & 2000 & \\
\hline
\end{tabular}


HNF-3329, Rev. 0

Appendix B. Annual 10- $\mathrm{m}^{\mathrm{a}}$ Peak Gust Data (mph) for Hanford Telemetering Stations with dates and times.

\begin{tabular}{|c|c|c|c|c|c|c|c|c|c|c|c|c|c|c|c|c|c|c|c|c|}
\hline \multirow{2}{*}{$\begin{array}{r}\text { Sta. } \\
1\end{array}$} & \multicolumn{4}{|c|}{1994} & \multicolumn{4}{|c|}{1995} & \multicolumn{4}{|c|}{1996} & \multicolumn{4}{|c|}{1997} & \multicolumn{4}{|c|}{1998} \\
\hline & 57.5 & (Nov & 30 & $17: 15)$ & 56.3 & (Feb & 16 & $12: 00)$ & 55.8 & ( Jan & 15 & $15: 45)$ & 67.6 & (Apr & 20 & $3: 45)$ & 48.2 & (Jan & 24 & $17: 45)$ \\
\hline 2 & 61.6 & (Nov & 29 & $23: 301$ & 74.6 & (Dec & 4 & $3: 00)$ & 60.2 & ( Jan & 3 & $9: 00)$ & 73.6 & (Jan & 1 & $0: 15)$ & 61.1 & Jan & 17 & $11: 15)$ \\
\hline 3 & 76.3 & (Nov & 30 & $13: 30)$ & 76.3 & (Dec & 12 & $23: 00)$ & 64.2 & (Feb & 22 & $22: 45)$ & 64.8 & loct & 30 & $8: 001$ & 55.3 & (Feb & 21 & \\
\hline 4 & 63.4 & (Nov & 30 & $13: 00)$ & 59.2 & (Dec & 12 & $23: 00)$ & 53.9 & (Sep & 15 & $14: 15)$ & 58.2 & loct & 30 & $9: 00)$ & 46.5 & (Jan & 5 & $12: 45)$ \\
\hline 5 & 44.4 & (Nov & 30 & $13: 30)$ & 54.5 & (Dec & 12 & $18: 45)$ & 47.9 & (Feb & 22 & $22: 30)$ & 57.6 & (Mar & 30 & $15: 45)$ & 62.4 & (Jul & 10 & $18: 30)$ \\
\hline 6 & 49.9 & loct & 26 & $14: 00)$ & 62.1 & (Dec & 12 & $19: 45)$ & 48.8 & (Eeb & 23 & $0: 45)$ & 61.7 & (Mar & 30 & $16: 00)$ & 47.7 & (Jun & 15 & $16: 15)$ \\
\hline 7 & 50.8 & (Nov & 30 & $14: 45)$ & 52.8 & (Dec & 4 & $5: 15)$ & 53.6 & (Eeb & 22 & $0: 00)$ & 57.4 & loct & 30 & $8: 00\}$ & 45.3 & (Jun & 15 & $15: 15)$ \\
\hline 8 & 53.9 & loct & 26 & $14: 15)$ & 55.7 & (Dec & 4 & $2: 45)$ & 54.1 & (Mar & 15 & $15: 4$ & 54.1 & (Apr & 20 & $3: 15)$ & 53.6 & (Jun & 15 & $18: 15)$ \\
\hline 9 & 56.9 & iNov & 30 & $17: 15)$ & 53.8 & (Nov & 29 & $6: 30)$ & 51.1 & (Apr & 23 & $19: 4$ & 62.8 & (Apr & 20 & & 43.6 & (Jun & 15 & \\
\hline 10 & 49.1 & (Nov & 30 & $14: 45)$ & 56.4 & (Dec & 4 & & 56.9 & (Feb & 22 & 21: & 57.8 & (Aug & 26 & 15: & 61.1 & (Apr & 6 & \\
\hline 11 & 49.6 & (Nov & 30 & $18: 3$ & 56.5 & (Dec & 12 & $21: 4$ & 52.3 & (Feb & 6 & $2:$ & 59.7 & (Mar & 30 & 16: & & May & 2 & \\
\hline 12 & 61.9 & (NOV & 30 & & 71.1 & (Feb & 16 & $7: 3$ & 65.4 & (Jan & 15 & $10: 00)$ & 60.4 & (Mar & 30 & $16: 15)$ & 47.6 & (Jun & 15 & $15: 45)$ \\
\hline 13 & 50.7 & (Nov & 30 & $13: 00)$ & 50.2 & (Dec & 12 & $21: 45)$ & 49.2 & $(\operatorname{Mar}$ & 15 & $10: 15)$ & 54.7 & (Apr & 3 & $15: 30)$ & 59.3 & (Jul & 29 & $13: 30)$ \\
\hline 14 & 60.1 & (Nov & 30 & $4: 30)$ & 57.0 & (Dec & 12 & $21: 45)$ & 58.3 & (Jan & 15 & $10: 30)$ & 59.7 & (Mar & 30 & $16: 15)$ & 53.7 & Jan & 23 & $22: 30)$ \\
\hline 15 & 53.5 & (Nov & 30 & $2: 30)$ & 56.1 & (Dec & 12 & $23: 15$ & 44.0 & (Feb & 5 & $23: 00)$ & 55.5 & (Jan & 11 & $22: 301$ & 41.8 & (Jun & 3 & $12: 00)$ \\
\hline 16 & 65.1 & loct & 26 & $14: 00)$ & 82.9 & (Dec & 12 & $22: 1$ & 63.7 & (Feb & 22 & $20: 5$ & 75.3 & (Mar & 30 & $15: 3$ & & (Jul & 10 & \\
\hline 17 & 43.1 & iNov & 30 & $17: 00)$ & 58.4 & (Feb & 16 & 10: & 53.3 & (Eeb & 5 & 23: & .0 & (Mar & 30 & 15: & .6 & (Jan & 17 & $12: 30)$ \\
\hline 18 & 60.1 & (Nov & 30 & $15: 30)$ & 62.8 & (Feb & 16 & $13: 30)$ & 54.5 & (Jan & 15 & $15: 45)$ & 60.9 & (Mar & 30 & $15: 45)$ & 49.0 & (Apr & 23 & $13: 15)$ \\
\hline 19 & 38.4 & (Nov & 30 & $15: 15)$ & 38.9 & (NOV & 29 & $5: 45)$ & 41.5 & (Feb & 23 & $0: 45)$ & 50.7 & 10ct & 30 & $9: 15)$ & 42.4 & (Jul & 10 & $19: 301$ \\
\hline 20 & 94.1 & loct & 26 & $14: 15)$ & 108.5 & (Dec & 4 & $3: 30)$ & 82.5 & (Feb & 22 & $23: 00)$ & 95.0 & (Apr & 20 & $7: 001$ & 100.0 & (Jan & 17 & $11: 30)$ \\
\hline 21 & 47.1 & (Nov & 30 & $15: 30)$ & 59.1 & (Dec & 12 & $22: 30)$ & 59.8 & $(\operatorname{Mar}$ & 7 & $14: 00)$ & 64.1 & loct & 30 & $8: 15)$ & 49.9 & (May & 21 & $20: 301$ \\
\hline 22 & 42.8 & (Nov & 30 & $20: 30)$ & 48.7 & loct & 3 & $12: 00$ & 44.8 & (Jan & 15 & $15: 30)$ & 52.9 & (Mar & 30 & $15: 4$ & 68.2 & (JuI & 10 & $19: 15)$ \\
\hline 23 & 47.8 & (Nov & 30 & $12: 45)$ & 50.3 & $10 \mathrm{ct}$ & 3 & $15: 3$ & 48.8 & (Apr & 23 & $19: 1$ & 51.8 & loct & 30 & $8: 1$ & 44.2 & (Jun & 13 & $16: 15)$ \\
\hline 24 & 47.1 & loct & 26 & $14: 00)$ & 61.6 & (Dec & 12 & $22: 15)$ & 48.3 & (Apr & 23 & $21: 30)$ & 56.2 & (Mar & 30 & $15: 451$ & 55.4 & (JUI & 10 & $18: 45)$ \\
\hline 25 & 48.3 & (Nov & 19 & $19: 45)$ & 60.6 & (Dec & 4 & $3: 15)$ & 52.7 & (Mar & 15 & $16: 15)$ & 61.2 & (Apr & 20 & $3: 451$ & 51.7 & iJun & 4 & $14: 15)$ \\
\hline 27 & 51.1 & (Nov & 30 & $20: 00)$ & 53.2 & (Nov & 29 & $15: 30)$ & 45.9 & (Jan & 15 & $15: 30)$ & 51.9 & (Apr & 20 & $6: 15)$ & 66.4 & (JuI & 10 & $19: 15)$ \\
\hline
\end{tabular}

a Except for stations 19 and 21. The Station 19 anemometer is at $8 \mathrm{ft}$, and the station 21 (HMS) anemometer is at $50 \mathrm{ft}$. 